\title{
Adaptability of Polymer-Containing Sewage Corrosion Inhibitor
}

\author{
Limei Sun, Chunxi Gao, Wenmiao Gao, Jie Cui, Jianhua Xu \\ Shengli Oil Production Plant of Shengli Oilfield Branch Company, SINOPEC, Dongying, China \\ Email: slmwky@163.com
}

How to cite this paper: Sun, L.M., Gao, C.X., Gao, W.M., Cui, J. and Xu, J.H. (2018) Adaptability of Polymer-Containing Sewage Corrosion Inhibitor. Journal of Materials Science and Chemical Engineering, 6, 70-80.

https://doi.org/10.4236/msce.2018.67008

Received: April 24, 2018

Accepted: July 1, 2018

Published: July 4, 2018

\begin{abstract}
The polymer content in the produced water from Tuoliu Station is about 20 $\mathrm{mg} / \mathrm{L}$. Cationic imidazoline-type corrosion inhibitor is used to corrosion control of sewage. The corrosion inhibitor can react with the negatively charged materials such as anionic polymer and suspended substance by adsorption and merging to form complex aggregates, so that the suspended solids content increases, resulting in suspended solids content of exported sewage has been high. So a new type of non-ionic corrosion inhibitor has been developed and field trials have been performed. The results show that non-ionic corrosion inhibitor can effectively reduce the suspended solids content of wastewater while ensuring the corrosion rate of wastewater.
\end{abstract}

\section{Keywords}

Polymer-Containing Sewage, Suspended Solids, Imidazoline Corrosion Inhibitor, Non-Ionic Corrosion Inhibitor, Strata Deficiency

\section{Introduction}

In the late stage of crude oil exploitation, especially during the period of ultra-high water-cut, most oilfields will implement oil recovery enhanced technologies to further reduce remaining oil saturation and increase oil recovery rate. The technologies for enhanced oil recovery, especially for chemical flooding, have been widely recognized that such as chemicals can cause oil-water separation difficulties, crude oil emulsification [1] [2] [3] and so on. Corresponding sewage treatment technologies also constantly updated to meet the needs of reservoir development. In view of the polymer-containing sewage, besides the gravity sedimentation and filtration process, the commonly used sewage treatment technology is flotation [4], coagulation, microorganism, etc., and basically achieves the standard injection of wastewater. 
Tuoliu Station of Shengli Oil Production Plant is a conventional water flooding treatment station. Since the end of 2014, the polymer concentration in produced liquid has risen. Since the end of 2015, suspended solids content has been high, which has been found to relate with the current use of cationic imidazoline-type corrosion inhibitor after a large number of on-site research and testing. The study on a new type of non-ionic corrosion inhibitor and field trials has been carried out. The results show that the non-ionic corrosion inhibitor can effectively reduce the suspended solids of wastewater while ensuring the corrosion rate of wastewater.

\section{Polymer Concentration in Sheng'er Sewage}

In Sheng'er District, the polymer injection for production was implemented in 2005. There are four projects for enhanced oil production from 2013 to 2016. Among them, Dong 3 (4) polymer injection has been the most effective, while the produced oil from Sha $2(83$ - 85) enhanced polymer flood was not significant due to the injection pressure exceeded the expected value. The low-tension nitrogen foam drive in Sha 2 (3) has been stopped in November 2015. At present, the Tuoliu sewage treatment station contains $2665 \mathrm{~m}^{3} / \mathrm{d}$ poly-produced fluid, accounting for about $13 \%$ of the total fluid volume.

Dong 3 (4) polymer injection has been the most effective. The highest polymer concentration is $180 \mathrm{mg} / \mathrm{L}$; the average value is about $110 \mathrm{mg} / \mathrm{L}$. Since the end of 2014, the polymer concentration reached $100 \mathrm{mg} / \mathrm{L}$, at the same time the sewage quality in Tuoliu Station deteriorated. Table 1 shows polymer concentration in some individual well fluid going to Tuoliu Station. Since the poly-produced fluid and the water-produced fluid are mixed in the combined station, the polymer in the wastewater is diluted. According to the poly-recovered fluid accounting for $13 \%$ of the total amount of the inbound station, the highest polymer content in the sewage station should be $14 \mathrm{mg} / \mathrm{L}$, the average should be $9 \mathrm{mg} / \mathrm{L}$. The polymer concentration in the sewage station was detected to be around $10 \mathrm{mg} / \mathrm{L}$, as shown in Table 2, which is consistent with the calculation result of the average polymer concentration. The detection of polymer content currently uses the colorimetric method of starch-iodide colorimetry. This method

Table 1. Polymer concentration in some individual well fluid going to tuoliu station.

\begin{tabular}{cccc}
\hline Team & Well & Horizon & Polymer concentration/(mg/L) \\
\hline 5 & ST2-1-16 & D341-D343 & 376 \\
5 & ST2-2-109 & D341-D343 & 42.5 \\
22 & ST2-2-153 & D341-D343 & 16 \\
22 & ST2-2-185 & D341-D343 & 221.5 \\
22 & STS2-88 & D341-D341 & 1540 \\
5 & STS2-89 & D341-D341 & 365 \\
5 & STS2X87 & D341-D343 & 128 \\
\hline
\end{tabular}


Table 2. Polymer concentration in Tuoliu station sewage.

\begin{tabular}{ccc}
\hline Sample & Polymer concentration $(\mathrm{mg} / \mathrm{L})$ & Date \\
\hline Inported sewage & 14.1 & 2014.12 \\
Exported ewage & $6 / 8$ & 2015.3 \\
\hline
\end{tabular}

has a large deviation [5], especially for the detection of polymer content in low-concentration production fluids that have taken a long time in the oil reservoir. According to the literature, the value measured by the ultrafiltration concentrated film drying method [5] should be about 2 times the detected value, that is, the polymer concentration in the sewage is about $20 \mathrm{mg} / \mathrm{L}$. Tuoliu Station sewage belongs to low polymer content produced water.

\section{Suspended Solids Index for Tuoliu Station Exported Sewage}

Since April 2014, the sewage at Tuoliu Station has turned into turbid. During the production, it has been found that filter screens were often blocked and the screens were frequently cleaned, which brought a lot of inconvenience to production. Compared with 2014, in January-October 2015, the suspended solids content in the exported sewage at Tuoliu Station increased, exceeding the standard requirement of $7 \mathrm{mg} / \mathrm{L}$. The compliance rate was only $55.38 \%$, which seriously affected the water quality index completed.

At the same time, there were 64 insufficient injection layers in Sheng'er district, and the water shortage was $2862 \mathrm{~m}^{3} / \mathrm{d}$, as shown in Figure 2. From the perspective of the sub-factors due to lack of injection layer, the pollution of the sewage water from the Tuoliu Station was the major cause of stratum incompetence, as shown in Figure 5. As the water quality did not reach the standard, the injection pressure gradually increased and the water absorption index gradually decreased. Taking the Sha'er $74-81$ unit as an example, the injection pressure increased from $11 \mathrm{MPa}$ in 2011 to $15.5 \mathrm{MPa}$, and the water absorption index was $104.1 \mathrm{~m}^{3} / \mathrm{d}$ in 2011. The decrease of MPa to $33.3 \mathrm{~m} / \mathrm{d} \cdot \mathrm{MPa}$ has an adverse effect on water flood development.

\section{Effect of Imidazoline Corrosion Inhibitor on Sewage Quality}

\subsection{Corrosion Inhibitor Structure}

The imidazoline corrosion inhibitor is a reaction product of a polyethylene polyamine and oleic acid, in which the polyethylene polyamine and oleic acid are both a mixture and are dehydrated at about $200^{\circ} \mathrm{C}$ to produce the substituted imidazoline shown below. $\mathrm{R}$ is shown as an unringed portion of the poly ethylene polyamine. The reaction was then quaternized with acetic acid. The structural formula is shown in Figure 1. The imidazoline corrosion inhibitor was added to the sewage treatment plant of Shengcai Plant, achieving a $98 \%$ compliance rate of the exported wastewater. 


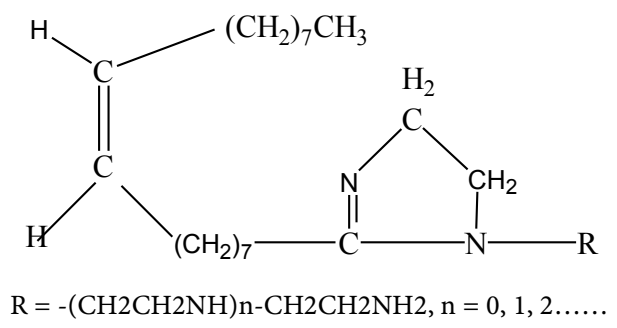

Figure 1. The structural formula of imidazoline corrosion inhibitor.

\subsection{Effect of Imidazoline Corrosion Inhibitor on the Quality of Polymer-Containing Sewage}

In experiment it was found that the water color of the sewage became turbid after the imidazoline corrosion inhibitor was added to the sewage at Tuoliu Station, as shown in Figure 2. The suspended solids content test was conducted on the sewage to which the imidazoline corrosion inhibitor was added. The blank sewage suspended solids content without any pharmaceutical agent was 13 $\mathrm{mg} / \mathrm{L}$. After adding the drug, the suspended matter content doubled, and the filtration time was also doubled, see Table 3.

It was considered that the change of the actual value above should be related to the inhibitor added, and the inhibitor will increase the suspended solids content. The corrosion inhibitor is a cationic imidazoline type, and can form a complex aggregate by the aggregation and adsorption of negatively charged substances such as anionic polymers and suspended substances in the system. In the suspension filtration experiment, agents, polymers, suspended solids, etc. may be retained together on the filter membrane, the quality of suspended solids is increased, that is, the apparent content of suspended solids increases.

In order to verify the impact of imidazoline corrosion inhibitors on the quality of sewage, a field test was conducted at the Tuoliu Station. All the filters were stopped and the inhibitor was added after the buffer tank as usual. The suspended solids content at the nodes along the station was tesed. From Figure 3 and Figure 4, it can be seen that from the inlet to the buffer tank, after the gravitational sedimentation process, the suspended solids content decreases in turn. However, from the buffer tank outlet to the station outlet, the suspended solids content increased significantly. Theoretically, when filters didn't work, there should be no big difference of suspended solids content between the buffer tank outlet and the station outlet. The change of the actual value should be related to the inhibitor added after the buffer tank, and the inhibitor will increase suspended solids content.

\section{Preparation and Effect of Non-Ionic Corrosion Inhibitors}

Due to the addition of quaternary ammonium acetate during the preparation of the imidazoline corrosion inhibitor, the imidazoline corrosion inhibitor has a cationic structure. The idea of non-ionic corrosion inhibitors is to connect the non-ionic polyoxyethylene block structure to the substituted group of the 


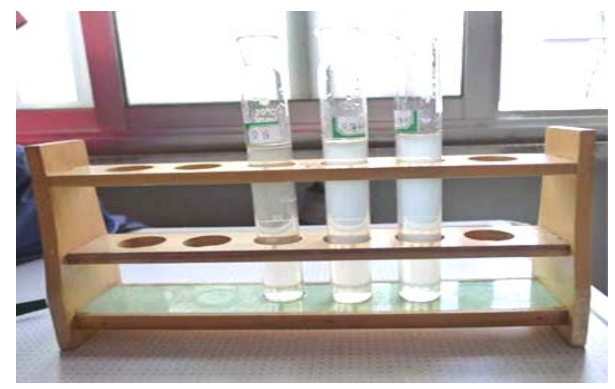

Figure 2. The sewage color after the imidazoline corrosion inhibitor was added.

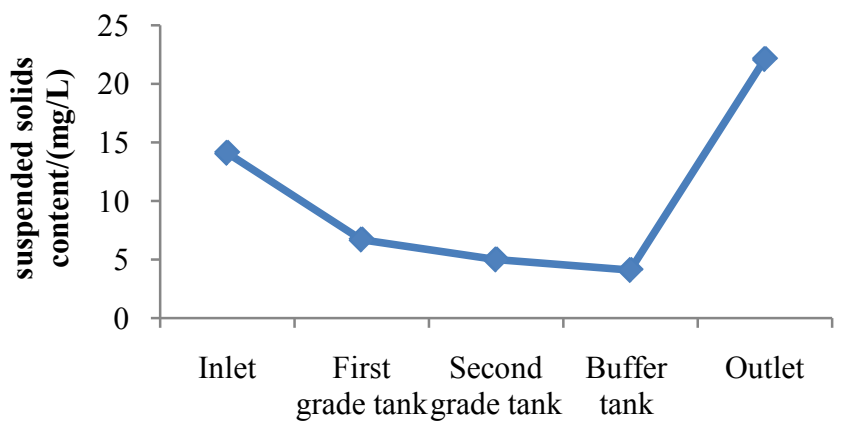

Figure 3. Variations of suspended solids content in Tuoliu sewage station.

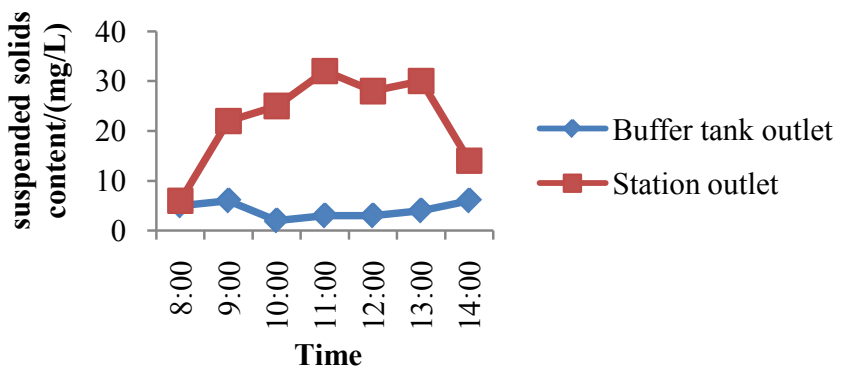

Figure 4. Change of suspended solids content at different sampling time for buffer tank outlet and outlet of Tuoliu Sewage station.

Table 3. Evaluation of the compatibility between sewage and additive chemcal.

\begin{tabular}{ccc}
\hline Index & sewage & Imidazoline corrosion inhibitor sewage 50 mg/L \\
\hline suspended solids content (mg/L) & 13 & 35 \\
Filtration time (min) & $20-30$ & $60-90$ \\
\hline
\end{tabular}

substituted imidazoline in order to avoid the interaction between the corrosion inhibitor and the anionic suspended solids and polymers in the sewage.

\subsection{Non-Ionic Corrosion Inhibitor Preparation}

1) The main raw materials and reagents

Polyethylene polyamines: industrial products; diethylenetriamine: analytically pure AR; oleic acid: industrial products; benzoic acid: analytically pure AR; ethylene oxide: industrial products. 
2) The synthesis process

1) Cyclization dehydration

The fatty acid, organic amine and water-carrying solvent (toluene or xylene) were added to the reactor with stirring, condenser, water separator and thermometer, and the temperature was raised to $120^{\circ} \mathrm{C}-160^{\circ} \mathrm{C}$. The reaction was continued at constant temperature for 2 hours, and the temperature was further increased to $200^{\circ} \mathrm{C}-260^{\circ} \mathrm{C}$, at constant temperature the reaction was continued for 3 hours. After the water was distilled out of the water-carrying agent, a brown viscous liquid was obtained as intermediate $\mathrm{A}$.

2) Etherification

The intermediate A was transferred to a reactor, an etherification catalyst was added, the air in the reactor was purged with $\mathrm{N} 2$, and the temperature was raised to $120^{\circ} \mathrm{C}$ to $150^{\circ} \mathrm{C}$. Ethylene oxide was added to the etherification reaction to adjust the reaction product properties. When the reaction was completed, after natural cooling, the reaction pressure is vented, and products are mixed with water and methanol to obtain a non-ionic corrosion inhibitor. The structure of the non-ionic corrosion inhibitor is shown in Figure 5. Where R is a C12 - C20 alkyl, alkenyl or phenyl group; $\mathrm{n}$ is an integer and $\mathrm{n} \geq 0$; $\mathrm{x}$ and $\mathrm{y}$ are integers greater than or equal to 0 and $5 \leq x+y \leq 15)$.

3) Synthesis condition optimization

In order to obtain a product with excellent performance, the proportion of raw materials was optimized, see Table 4. The product image is shown in Figure 6. The product analysis and test results are shown in Table 5.

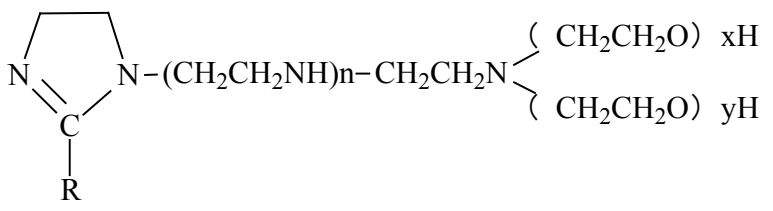

Figure 5. The structure of the non-ionic corrosion inhibitor.

Table 4. Proportion of raw materials optimization.

\begin{tabular}{lcc}
\hline No. & Raw materials & Fatty acids: organic amine: ethylene oxide \\
\hline 01 & Oleic Acid, & $2: 1: 4$ \\
02 & polyethylene Polyamines, & $2: 1: 7$ \\
03 & ethylene Oxide & $1: 1: 4$ \\
04 & & $1: 1: 7$ \\
05 & Oleic acid, & $1: 1: 4$ \\
06 & diethylenetriamine, ethylene oxide & $1: 1: 7$ \\
07 & & $2: 1: 4$ \\
08 & Benzoic Acid, & $2: 1: 7$ \\
09 & polyethylene Polyamines, & $1: 1: 4$ \\
10 & ethylene Oxide & $1: 1: 7$ \\
11 & & $1: 1: 4$ \\
12 & diethylenetriamine, ethylene oxide & $1: 1: 7$ \\
\hline
\end{tabular}




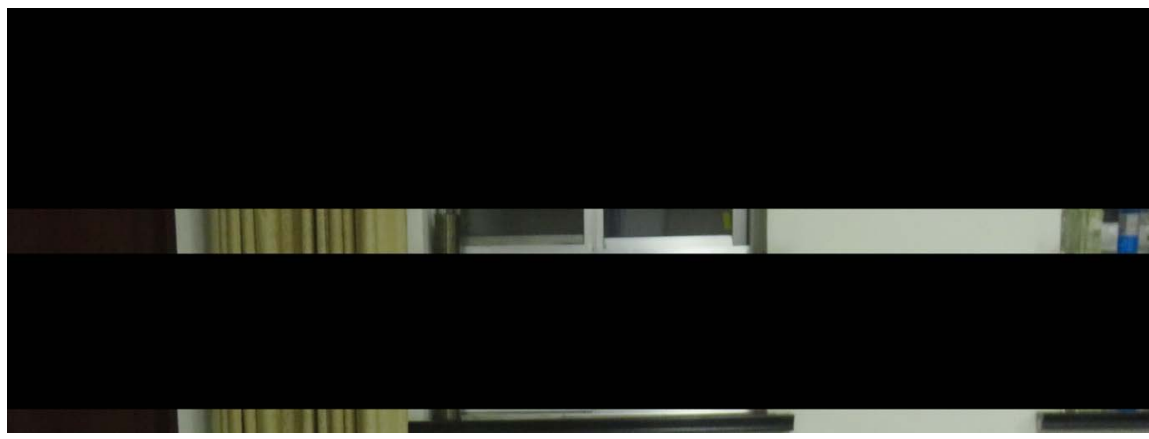

Figure 6. Products.

Table 5. Product analysis and test results.

\begin{tabular}{|c|c|c|c|c|c|c|c|c|}
\hline \multirow{3}{*}{ Test items } & \multirow{3}{*}{ Unit } & \multirow{3}{*}{$\begin{array}{l}\text { Standard } \\
\text { indicators }\end{array}$} & \multicolumn{6}{|c|}{ Date } \\
\hline & & & 1 & 2 & 3 & 4 & 5 & 6 \\
\hline & & & 7 & 8 & 9 & 10 & 11 & 12 \\
\hline \multirow[b]{2}{*}{ Appearance } & & \multirow[b]{2}{*}{ Homogeneous } & $\times$ & $\sqrt{ }$ & $\sqrt{ }$ & $\sqrt{ }$ & $x$ & $\sqrt{ }$ \\
\hline & & & $x$ & $x$ & $x$ & $\sqrt{ }$ & $x$ & $x$ \\
\hline \multirow{2}{*}{$\mathrm{pH}$} & & \multirow{2}{*}{$6.5-7.5$} & - & 7.0 & 7.0 & 7.0 & - & 7.0 \\
\hline & & & - & - & - & 7.0 & - & - \\
\hline \multirow{2}{*}{ Solidifying point } & \multirow{2}{*}{${ }^{\circ} \mathrm{C}$} & \multirow{2}{*}{$\leq-10$} & - & -12 & -13 & -12 & - & -13 \\
\hline & & & - & - & - & -12 & - & - \\
\hline \multirow{3}{*}{ Open flash point } & \multirow{3}{*}{${ }^{\circ} \mathrm{C}$} & \multirow{3}{*}{$\geq 50$} & - & 52 & 51 & 52 & - & 53 \\
\hline & & & & & & 1 & & \\
\hline & & & & & & & & \\
\hline \multirow{2}{*}{ Water soluble } & \multirow{2}{*}{\multicolumn{2}{|c|}{ good }} & - & $\sqrt{ }$ & $\sqrt{ }$ & $\sqrt{ }$ & - & $\sqrt{ }$ \\
\hline & & & - & - & - & $\sqrt{ }$ & - & - \\
\hline \multirow[b]{2}{*}{ Effective content } & \multirow[b]{2}{*}{$\%$} & \multirow[b]{2}{*}{$\geq 20$} & 20 & 20 & 20 & 20 & 20 & 20 \\
\hline & & & 20 & 20 & 20 & 20 & 20 & 20 \\
\hline \multirow{2}{*}{ Emulsification tendency } & \multirow{2}{*}{\multicolumn{2}{|c|}{ none }} & - & none & none & none & - & none \\
\hline & & & - & - & - & none & - & - \\
\hline \multirow{2}{*}{$\begin{array}{l}\text { Corrosion Inhibition } \\
\text { (Corrosion Inhibition Rate) }\end{array}$} & \multirow{2}{*}{$\%$} & \multirow{2}{*}{$\geq 70$} & - & 76 & 83 & 95 & - & 85 \\
\hline & & & - & - & - & 55 & - & - \\
\hline \multirow{2}{*}{$\begin{array}{l}\text { Inhibition performance } \\
\text { (point corrosion) }\end{array}$} & & \multirow{2}{*}{$\begin{array}{c}\text { No obvious } \\
\text { point corrosion }\end{array}$} & - & none & none & none & - & none \\
\hline & & & - & - & - & $\sqrt{ }$ & - & - \\
\hline \multirow{2}{*}{ Organic chlorine content } & \multirow{2}{*}{$\%$} & \multirow{2}{*}{0.0} & 0 & 0 & 0 & 0 & 0 & 0 \\
\hline & & & 0 & 0 & 0 & 0 & 0 & 0 \\
\hline
\end{tabular}

1. Tuoliu station water was used to the corrosion performance; 2. “-”: not evaluated.

It can be seen from Table 5 that the performance of products 2, 3, 4, and 6 meet the requirements of Q/SHCG 40-2012 < Technical Requirements for Corrosion Inhibitors for Oilfield Produced Water Treatment $>$. As can be seen from Figure 6, the 4\# sample is a homogeneous liquid form. According to the actual 
application, the impact of the product on the suspended solids content of Tuoliu Sewage was evaluated, see Table 6 for details. It can be seen from Table 6 that products 4 and 6 have no effect on the suspended solids index of Tuoliu Sewage, while products 2 and 3 have a greater impact.

Polyethylene polyamines and diethylene triamines are comparable in price, but their molecular weights are quite different, with molecular weights of 220 (average molecular weight) and 103, respectively. Since the properties of the products synthesized by polyethylene polyamines and diethylene triamines are comparable, diethylenetriamine is more volatile than polyethylene polyamines, so in terms of safety and environmental protection, product 4 is selected as the final product.

\subsection{Non-Ionic Corrosion Inhibitor Field Test}

The field test of non-ionic corrosion inhibitors was selected at the Tuoliu Station and the time was from 2016.12.04 to 2016.12.20 for a total of 16 days. The dosing amount and the dosing position are the same as the existing corrosion inhibitor (ie, the concentration of the drug is $30 \mathrm{mg} / \mathrm{L}$, and the dosing position is the buffer outlet), and the existing corrosion inhibitor is added 3 days before the test period (12.04 to 12.07). Non-ionic corrosion inhibitors were added 15 days later. The test data are shown in Table 7 and Table 8.

It can be seen from Table 7 that the application of non-ionic corrosion inhibitors greatly improved the suspended solids index of the exported sewage, from about $30 \mathrm{mg} / \mathrm{L}$ before use to $10 \mathrm{mg} / \mathrm{L}$; and Table 8 and Figure 7 show that: The use of non-ionic corrosion inhibitors will not affect the corrosion indicators of exported sewage.
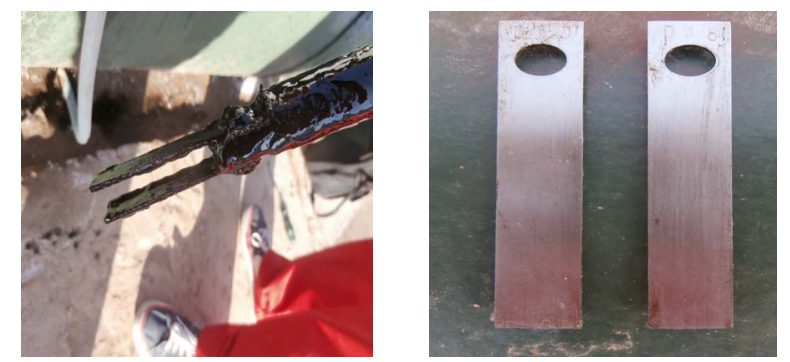

Figure 7. Appearance of corrosion indicators in sewage when non-ionic corrosion inhibitor was tested.

Table 6. The impact of the product on the suspended solids content of Tuoliu sewage.

\begin{tabular}{ccc}
\hline No. & Dose $(\mathrm{mg} / \mathrm{L})$ & suspended solids content $(\mathrm{mg} / \mathrm{L})$ \\
\hline Blank & 0 & 12 \\
2 & 30 & 25 \\
3 & 30 & 30 \\
4 & 30 & 11 \\
6 & 30 & 12 \\
\hline
\end{tabular}


Table 7. Sewage water quality data of Tuoliu Station during non-ionic corrosion inhibitor field test.

\begin{tabular}{|c|c|c|}
\hline Date & Time & suspended solids content $(\mathrm{mg} / \mathrm{L})$ \\
\hline \multirow{2}{*}{2016.12 .04} & 08:00 & 30 \\
\hline & $16: 00$ & 28 \\
\hline \multirow{2}{*}{2016.12 .05} & 08:00 & 31 \\
\hline & $16: 00$ & 35 \\
\hline \multirow{2}{*}{2016.12 .06} & 08:00 & 29 \\
\hline & $16: 00$ & 33 \\
\hline \multirow{2}{*}{2016.12 .07} & 08:00 & 28 \\
\hline & $16: 00$ & 12 \\
\hline \multirow{2}{*}{2016.12 .08} & 08:00 & 11 \\
\hline & $16: 00$ & 13 \\
\hline \multirow{2}{*}{ 2016.12.09 } & 08:00 & 14 \\
\hline & $16: 00$ & 10 \\
\hline \multirow{2}{*}{2016.12 .10} & 08:00 & 13 \\
\hline & $16: 00$ & 12 \\
\hline \multirow{2}{*}{2016.12 .11} & 08:00 & 12 \\
\hline & $16: 00$ & 13 \\
\hline \multirow{2}{*}{2016.12 .12} & 08:00 & 11 \\
\hline & $16: 00$ & 10 \\
\hline \multirow{2}{*}{2016.12 .13} & 08:00 & 13 \\
\hline & $16: 00$ & 11 \\
\hline \multirow[b]{2}{*}{2016.12 .14} & 08:00 & 9 \\
\hline & $16: 00$ & 10 \\
\hline \multirow{2}{*}{2016.12 .15} & 08:00 & 11 \\
\hline & $16: 00$ & 12 \\
\hline \multirow{2}{*}{2016.12 .16} & 08:00 & 10 \\
\hline & $16: 00$ & 13 \\
\hline \multirow{2}{*}{2016.12 .17} & 08:00 & 12 \\
\hline & $16: 00$ & 8 \\
\hline \multirow{2}{*}{2016.12 .18} & 08:00 & 13 \\
\hline & $16: 00$ & 11 \\
\hline \multirow{2}{*}{2016.12 .19} & 08:00 & 10 \\
\hline & $16: 00$ & 12 \\
\hline \multirow{2}{*}{2016.12 .20} & 08:00 & 13 \\
\hline & $16: 00$ & 12 \\
\hline
\end{tabular}


Table 8. Corrosion rate of exported sewage during the non-ionic corrosion inhibitor field test.

\begin{tabular}{ccc}
\hline Period & Days & Corrosion rate, $\mathrm{mm} / \mathrm{a}$ \\
\hline $2016.11 .8-2016.11 .20$ & 12 & 0.0399 \\
$2016.11 .24-2016.12 .06$ & 13 & 0.0317 \\
$2016.12 .07-2016.12 .20$ & 13 & 0.0298 \\
\hline
\end{tabular}

\section{Conclusions and Recommendations}

\subsection{Conclusion}

The polymer concentration in the produced water at the Tuoliu station is about $20 \mathrm{mg} / \mathrm{L}$, and the corrosion inhibitor is a cationic imidazoline type. It can form complex aggregates with the negatively charged substances such as anionic polymers and suspended solids in the system, the amount of suspended solids content is increased. By replacing the cationic corrosion inhibitor with a non-ionic corrosion inhibitor, the interaction between the polymer and the corrosion inhibitor is weakened, and the suspended solids content in the sewage is reduced.

\subsection{Suggestions}

At present, the suspended solids content for the exported sewage at Tuoliu Station still does not reach the standard. The main reason is that the filtration process is not perfect. First, an external wash basin is much less than the configuration requirements of 8 filters. Second, there is no backwash treatment process at the Tuoliu stations. At present, backwash water is still used to directly enter the oil station without treatment. Some of the impurities in the water station system cycles to add burden to the water station system. Third, the filter process uses walnut shell filter material, and the removal effect of suspended solids may be insufficient. It is recommended to increase the number of filters, increase the backwashing equipment, construct the backwashing treatment process, and select the appropriate filter material to achieve the standard reinjection of wastewater.

\section{Acknowledgements}

Thanks to Shengli Oil Production Plant of Shengli Oilfield Branch Company, SINOPEC for funding this research.

\section{References}

[1] Liu, Y., Wang, Z.H., Xu, M.M., et al. (2017) Emulsification Behavior and Electro-Chemical Dehydration Method of Produced Liquid in High Concentration Polymer Flooding Wells. Journal of Southwest Petroleum University (Science \& Technology Edition), 39, 177-184.

[2] Du, Z.Q. (2016) Research on High-Efficiency Demulsification Technology of Polymer-Containing Crude Oil. Xi'an University, Xi'an.

[3] Chen, J.J. and Wang, F.H. (2009) Produced Fluid Treatment Technology of Foam 
Combination Flooding in West Area of Chengdong Oilfield. Complex Hydrocarbon Reserviors, No. 1, 61-64.

[4] Gao, J.Q., Ding, H., Xu, S.L., et al. (2010) High-Grade Agglomerated Air Flotation Method and Device for Treating Polymer-Containing Wastewater, CN101863562A.

[5] You, Q., Zhao, F.L., Mu, L.N., et al. (2007) A New Method for the Accurate Determination of Polyacylaminde Concentration in Produced Fluids of Polymer Flooding Oil Well: A Film Drying Method after Ultrafiltration and Condensation. ACTA Petroleum Sinica (Petroleum Processing Section), 23, 109-113. 